\title{
Saberes tradicionais de jovens e adultos e a presença de conceitos geométricos em Tracuateua/PA
}

\author{
Rogerio Andrade Maciel* \\ Universidade Federal do Pará \\ Edilene Farias Rozal** \\ Universidade Federal do Pará
}

Resumo O presente artigo tem como objetivo identificar os saberes tradicionais existentes no artesanato produzido por jovens e adultos quilombolas e a presença de conceitos geométricos na comunidade do Jurussaca, em Tracuateua/PA. Os autores que balizam as análises são: Castro (1997), Freire (1996), D’Ambrósio (2007). Metodologicamente utilizou-se a abordagem qualitativa, numa perspectiva do enfoque fenomenológico, utilização de entrevistas, observação e fotografias como forma de coleta de dados, e registro visual sobre a produção do artesanato. Nas análises deste estudo, observou-se que existem três produtos que os artesões fabricam para a utilização da pesca artesanal e da agricultura familiar, são eles: o cofo, o paneiro e o socó. Há evidências de que nestes produtos artesanais, usados na ocupação econômica da comunidade, emergem saberes e práticas tradicionais que possibilitam a construção de figuras geométricas planas e o reconhecimento das experiências de vida dos jovens e adultos em suas dimensões culturais, sociais e históricas presentes no cotidiano desta comunidade.

PALAVRAS-CHAVE: Saberes tradicionais; Educação de jovens e adultos quilombolas; Etnomatemática. 


\section{Traditional knowledge of youth and adults and the presence of geometric concept in Tracuateua/PA}

Abstract The present article has as its aims identify the traditional knowledge that exists in handcraft produced by youth and adult quilombola's people and the presence of geometric concepts in the community of Jurussaca, at Tracuateua/PA. The authors who base the analysis are: Castro (1997), Freire (1996), D’Ambrósio (2007). Methodologically was used a qualitative approach from a perspective of the phenomenological focus, the use of interviews, observation and photographs as a way of collecting data and a visual record about the production of handicrafts. In the analyzes of this study, it was observed that there are three products that artisans make for the use of artisanal fishing and family farming, they are: cofo, paneiro and socó. There is an evidence that in these craft products, used in the economic occupation of the community, emerge knowledge and traditional practice that allow the construction of flat geometric figures and the recognition of the life experiences of youth people and adults in their cultural, social and historical dimensions present in the daily life of this community.

KEYWORDS: Traditional knowledge; Education of youth and adult quilombola's people; Ethnomathematics.

\section{Introdução}

Considerando que na comunidade quilombola do Jurussaca em Tracuateua - PA, existem saberes tradicionais no artesanato produzido por jovens e adultos que se configuram em conceitos geométricos, estes precisam obter uma visibilidade para a produção do conhecimento no cotidiano escolar.

O referido artigo iniciou-se pela presença de uma rica cultura quilombola, que induz a uma ruptura de uma única roupagem de Educação Matemática e esclarece as diversas formas de saberes tradicionais que são construídos pelos jovens e adultos quilombolas, pelo viés dos conceitos geométricos, inclusive na comunidade quilombola do Jurussaca, legalmente reconhecida pelo Governo Federal no município de Tracuateua, Nordeste Paraense.

Metodologicamente para realização deste estudo utilizou-se a abordagem qualitativa do tipo fenomenológico, que segundo Chizzotti (2001, p. 80) pode ser visualizada como "a ciência dos fenômenos, que a partir da consciência do mundo interior desvenda o fenômeno além da aparência", isso porque os fenômenos nem sempre são como se apresentam, necessitando assim buscar sua essência para descrever melhor o objeto pesquisado. Este objeto perpassa pelos saberes tradicionais dos jovens e adultos na produção do artesanato e a presença dos conceitos geométricos na comunidade do Jurussaca. 
Como procedimentos, foram operacionalizados: as entrevistas, observação participante, como forma de coleta de dados, e a utilização de fotografias como registro visual. Assim, para realização deste estudo, optou-se, no universo da comunidade, trabalhar com os moradores mais antigos $(=08)$, a fim de se obter informações sobre os saberes tradicionais matemáticos e, os jovens dedicados às práticas culturais do artesanato $(=05)$, para constatar o processo da manutenção desses saberes. Também foram envolvidos professores $(=02)$ da escola existente na comunidade, para saber como a educação formal está relacionando o conhecimento matemático formal com os saberes tradicionais.

\title{
Diálogos sobre saberes tradicionais desenvolvidos pelos jovens e adultos quilombolas
}

Os diálogos sobre os saberes tradicionais desenvolvidos por jovens e adultos estão constituídos pela relação das populações tradicionais com o meio ambiente. Para Castro (1997), a capacidade do homem em transformar suas relações com a natureza e modificá-las de acordo com as suas necessidades é muito presente quando o território apresenta um conjunto de recursos ao qual o homem deseja e o utiliza em suas práticas tradicionais do cotidiano.

Castro (1997) reafirma que as discussões sobre populações tradicionais estão correlacionadas com a presença do espaço social, é nesse espaço em que o ser humano constrói e reconstrói os seus significados. Isso, a autora aborda quando:

\begin{abstract}
Observa-se ao longo da literatura sobre o tema que grupos nos países amazônicos - índios, castanheiros, seringueiros, pescadores artesanais, etc. São capazes de identificar com enorme riqueza de detalhes as diferenciações de fauna e de flora no interior da floresta, como a diversidade de espécies de peixes dos rios dos igarapés, dos lagos. Mas também de sons produzidos nas matas e suas diferenças em relação ao fato de ser noite ou dia, o mesmo em relação a movimentos e odores. Tais grupos distinguem uma série de complexos inerentes ao ecossistema (CASTRO, 1997, p. 226).
\end{abstract}

Sobre esta afirmação nota-se que a população grupal está literalmente atrelada ao território, no sentido de construir as definições dos lugares e relações de concepções que constroem no decorrer dos tempos com a natureza, o que caracteriza o conhecimento construído sobre um determinado território.

De acordo com Freire (2001), os jovens e adultos produzem conhecimentos que devem ter visibilidades a partir de seus territórios, culturas, saberes e práticas cotidianas. Entretanto, muitas vezes são invisibilizados porque não são dialogados nos currículos das escolas, suas identidades agro-pesqueira, da agricultura e outras práticas socioculturais, como os saberes tradicionais do artesanato.

É no respeito e na valorização dos saberes e práticas tradicionais dos sujeitos, na produção do artesanato, que podemos dizer que há uma produção do conhecimento matemático por uma tradição de seu povo que se faz e se refaz no cotidiano da realidade complexa e contraditória (FREIRE, 2001). 
Para Castro (1997, p. 224), a complexidade territorial em que se discute está baseada em duas abordagens: a primeira, no âmbito do território por uma ideologia técnico-econômica, fruto do processo capitalista, onde o homem exerce o poder sobre a natureza sem levar em consideração o grau de periculosidade que está cometendo sobre o ecossistema, "desqualificando e desvalorizando todos os saberes e suas práticas" o que implica assim na perda dos saberes tradicionais.

A segunda abordagem que Castro (1997) argumenta, é a que chama mais a atenção do leitor, vista que é a fonte da discussão para este estudo, trata-se da relação do homem com a natureza levando em consideração as diferentes formas de construção dos saberes com a complexidade do ecossistema que se constitui em saberes tradicionais, repletos de significados pelas populações tradicionais.

Para Castro (1997):

A natureza apresenta-se imediatamente ao conhecimento desses grupos, como um lugar de permanente observação, pesquisa e reprodução de saberes. A capacidade de classificar segundo categorias os objetos reais importa numa construção de significados para o processo de construção (IBID, 1997, p. 227).

Sobre essa vertente natural é que a maioria dos grupos se relaciona com o lugar, criando assim uma concepção ecológica dos recursos naturais, o que possibilita a produção da especificidade do trabalho em que o homem tem e a responsabilidade de interagir e respeitar à diversidade biológica.

Por isso, todas as atividades construídas pelos grupos sociais passam a constituir no território, "relações múltiplas que reúnem elementos técnicos como o mágico, o ritual, a produção, a construção social e o simbólico, formando assim, as populações tradicionais" (CASTRO, 1997, p. 238). Essa relação no seu espaço territorial passa por uma atividade de produção de saberes tradicionais.

Portanto, são essas diferentes maneiras de perceber a população e suas relações com a natureza que se constroem os fenômenos dos saberes tradicionais, frutos de experiências marcadas por uma identidade que passam de geração a geração nas comunidades quilombolas.

\section{Reflexões envolvendo quilombolas, etnomatemática, saberes e práticas tradicionais na produção do artesanato}

As comunidades quilombolas no Brasil, na Região Norte e no Estado do Pará, serão fontes indubitavelmente preciosas para entender o reflexo dos conhecimentos dos povos africanos e sua influência no território brasileiro.

Sabe-se que durante a colônia criaram-se estereótipos da população indígena e negra, visto assim como fator negativo pela população eurocêntrica. O que passou a se converter como um aspecto de imposição de pensamentos sobre a cultura nativa indígena e escravizada da época (negros), ambos eram vistos como populações que não podiam contribuir com sua cultura nem saber sistematizado ou relevante para a sociedade civilizatória. 
Essa ideia começou a ficar claro para os invasores, quando os negros e nativos resistiriam ao projeto de dominação que havia sido imposto pelo colonizador, pois a prática civilizatória passava por uma dupla intervenção desqualificadora: desacreditar os saberes e valores que eles praticavam para logo "rehumanizá-los" (à força, basicamente) através da imposição dos saberes e valores ocidentais dominantes (CARVALHO, 2007, p.02).

É possível notar que esta imposição eurocêntrica possibilitou ou causou a perda de inúmeras referências simbólicas desses grupos indígenas e negros. Entretanto, foi essa imposição que acabou levando os povos - negros e indígenas - a uma prática de resistência o que contribuiu para garantir, mesmo com uma ruptura de alguns conhecimentos, a permanência dos saberes, valores, referências e maneiras dos próprios grupos humanos.

Os colonizadores europeus começaram a trazer também milhares de africanos escravizados para o trabalho forçado, anos após ano, por mais de 300 anos (chegando a mais de 12 milhões de pessoas). Como no caso dos povos originários, as populações escravizadas pertenciam a centenas de nações diferentes que viviam por séculos em seus territórios tradicionais no interior do continente africano. A desqualificação dos africanos escravizados (tanto em sua sabedoria quanto em sua humanidade em geral). Foi de início, ainda mais dramática que a dos indígenas, visto que eles tiveram muito menos elementos próprios em que se apoiar para iniciar um movimento mínimo de resistência contra o horroroso regime a que foram submetidos contra a sua vontade (CARVALHO, 2007, p.01).

Essa prática de colonização que desqualificava os fatores simbólicos da população negra perpassou por dois momentos: de um lado, a resistência cultural dos negros, e por outro lado, as violências e repressões eurocêntricas que os tornaram marginalizados. Nesta relação, a resistência dos africanos na América repercutiu na formação dos quilombos.

São a partir de lutas e reivindicações históricas que as comunidades quilombolas vêm obtendo os seus direitos, por um sentimento de permanência sobre os seus valores culturais e sociais, relacionados com a produção agrícola, a construção do artesanato, uma religião provinda do próprio grupo, uma relação de preservação e conservação com o meio ambiente, ou seja, pontos inevitáveis que caracterizam a identidade do povo africano.

Segundo Schmitt; Turatti; Carvalho (2002), as comunidades quilombolas no Brasil não pertencem somente a um passado escravista ou a uma comunidade isolada, no tempo e no espaço, sem qualquer participação em sua estrutura social.

Ao contrário, as mais de 2 mil comunidades quilombolas espalhadas pelo território brasileiro mantêm-se vivas e atuantes, lutando pelo direito de propriedade de suas terras consagrado pela Constituição Federal desde 1988. Existem comunidades quilombolas vivendo em pelo menos 24 estados do Brasil: Amazonas, Alagoas, Amapá, Bahia, Ceará, Espírito Santo, Goiás, Maranhão, Mato Grosso, 
Mato Grosso do Sul, Minas Gerais, Pará, Paraíba, Pernambuco, Paraná, Piauí, Rio de Janeiro, Rio Grande do Norte, Rio Grande do Sul, Rondônia, Santa Catarina, São Paulo, Sergipe e Tocantins (COMISSÃO PRÓ - ÍNDIO DE SÃO PAULO, 2016, p. 02).

Neste sentido percebe-se a preocupação de lutas políticas destinadas para as populações quilombolas, pois essa formação tanto étnica, cultural, territorial e de saberes tradicionais como do artesanato, são constituídos em todo território brasileiro. Além do que, foi principalmente com a Constituição Federal de 1988 que a questão quilombola entrou na agenda das políticas públicas. Fruto da mobilização do movimento negro, o Artigo 68 do Ato das Disposições Constitucionais Transitórias (ADCT) diz que:

As comunidades de quilombos que estejam ocupando suas terras é reconhecida a propriedade definitiva, devendo o Estado emitirlhes os respectivos títulos (SCHMITT; TURATTI; CARVALHO, 2002, p. 01).

A concretização desse direito suscitou logo de início um acalorado debate sobre o conceito de quilombo, trabalhar com uma conceituação adequada fazia-se fundamental, já que era isso o que definiria quem teria ou não o direito à propriedade da terra. Ainda por este viés, deste modo, as comunidades de quilombo são grupos sociais cuja identidade étnica os distingue do restante da sociedade.

Segundo a Comissão Pró-Índio de São Paulo (2016), estima-se que hoje no Pará existem mais ou menos 250 comunidades quilombolas. Apesar dos quilombos do Pará serem pouco evidenciados na história brasileira, o grau de evidências de várias comunidades quilombolas chama a atenção pela própria dinâmica de que na Amazônia os negros contribuíram para a economia local. Isso porque:

Nas várias regiões do atual Estado do Pará, os negros foram utilizados como mão-de-obra nas atividades agrícolas e extrativistas, nos trabalhos domésticos e nas construções urbanas (COMISSÃO PRÓ - ÍNDIO DE SÃO PAULO, 2016, p. 01).

Percebe-se que no Pará, os quilombolas além de contribuir para manutenção e sustentabilidade da economia local, de uma maneira ou de outra, influenciaram na sustentabilidade da Amazônia. O que resultou também em inúmeras conquistas. Uma delas:

Foi no Pará, no Município de Oriximiná, que pela primeira vez uma comunidade quilombola recebeu o título coletivo de suas terras, no ano de 1995. E é nesse Município que se concentra o maior número de terras quilombolas tituladas desde 1998, o Pará conta com uma legislação que regulamenta o processo de titulação dessa categoria de terras (COMISSÃO PRÓ - ÍNDIO DE SÂO PAULO, 2016, p. 02).

Baseado nesta argumentação a história das comunidades quilombolas não pode ser esquecida no tempo sem levar em consideração a construção desses saberes tradicionais provindos de sua origem africana, e seus novos hábitos que foram redimensionados na colônia brasileira. Tudo isso fez com que na resistência de práticas de 
liberdade as comunidades quilombolas recebessem várias conquistas, como a legalização de suas terras, reconhecimento de sua cultura (saberes tradicionais) que se tem hoje no Estado do Pará.

Segundo as terras tituladas pelo Instituto de Terras do Pará (ITERPA), entre o período de 1998 e 2010, existem 41 comunidades quilombolas reconhecidas no Nordeste Paraense. No ano de 2017 o número de comunidades quilombolas aumentaram de um total de 168 áreas tituladas pelo Brasil e reconhecidas pelo Governo Federal, 58 áreas tituladas são do Estado do Pará. O que significa dizer que o Pará é o Estado que mais demarcou territórios quilombolas no Brasil. De acordo com o órgão ITERPA, isto se deve por uma política comprometida com as populações tradicionais, seus saberes produzidos no cotidiano e o diálogo entre os órgãos do governo com as associações das comunidades quilombolas do Pará.

O quadro (01), a seguir, demonstra algumas terras quilombolas no Estado do Pará - suas comunidades, números de família, área (ha), municípios, órgão expedidor e seus respectivos anos:

Quadro 01: comunidades quilombolas no Estado do Pará.

\begin{tabular}{|c|c|c|c|c|c|c|}
\hline $\begin{array}{c}\text { Terra } \\
\text { Quilombola }\end{array}$ & Comunidade(s) & Famílias & Área (ha) & Município & $\begin{array}{l}\text { Orgão } \\
\text { Expedidor }\end{array}$ & Ano \\
\hline Itamoari & Itamoari & 33 & $5.377,60$ & $\begin{array}{c}\text { Cachoeira } \\
\text { do Piriá }\end{array}$ & INCRA & 1998 \\
\hline Camiranga & Camiranga & 39 & 320,61 & $\begin{array}{c}\text { Cachoeira } \\
\text { do Piriáa }\end{array}$ & ITERPA & 2002 \\
\hline $\begin{array}{l}\text { Laranjituba - } \\
\quad \text { África }\end{array}$ & $\begin{array}{l}\text { Laranjituba e } \\
\quad \text { Átrica }\end{array}$ & 48 & 118,04 & Moju & ITERPA & 2002 \\
\hline $\begin{array}{c}\text { llhas de } \\
\text { Abaetetuba }\end{array}$ & $\begin{array}{c}\text { Alto e Baixo } \\
\text { Itacuruça, } \\
\text { Campopema, } \\
\text { Jenipaúba, } \\
\text { Acaraqui, } \\
\text { Igarapé São } \\
\text { João, Arapapu } \\
\text { e Rio Tauaré- } \\
\text { Açu }\end{array}$ & 116 & $11,458,53$ & Abaetetuba & ITERPA & 2002 \\
\hline Bom Remédio & Bom Remédio & 701 & 88,17 & Abaetetuba & ITERPA & 2002 \\
\hline Bailique & $\begin{array}{c}\text { Bailique Beira, } \\
\text { Bailique Centro, } \\
\text { Poção e Săo } \\
\text { Bernardo }\end{array}$ & 112 & $7.297,69$ & $\begin{array}{c}\text { Oeiras do } \\
\text { Pará e } \\
\text { Baiẫo }\end{array}$ & ITERPA & 2002 \\
\hline Jurussaca & Jurussaca & 45 & 200,99 & Traquateua & ITERPA & 2002 \\
\hline $\begin{array}{l}\text { Santa Rita de } \\
\text { Barreiras }\end{array}$ & $\begin{array}{l}\text { Santa Rita de } \\
\text { Barreiras }\end{array}$ & 35 & 30 & $\begin{array}{l}\text { São Miguel } \\
\text { do Guamá }\end{array}$ & PA & 2002 \\
\hline $\begin{array}{c}\text { Santa Fé e Santo } \\
\text { António }\end{array}$ & $\begin{array}{c}\text { Santa Fé e } \\
\text { Santo António }\end{array}$ & 28 & 830,88 & Baião & ITERPA & 2002 \\
\hline
\end{tabular}


Continuação do Quadro 1

\begin{tabular}{|c|c|c|c|c|c|c|}
\hline $\begin{array}{c}\text { Igarapé Preto e } \\
\text { Baixinha }\end{array}$ & $\begin{array}{l}\text { Igarapé Preto, } \\
\text { Baixinha, } \\
\text { Panpelônia, } \\
\text { Teófilo, } \\
\text { Varzinha, } \\
\text { Campelo, Cupu, } \\
\text { França, } \\
\text { Araquenbaua, } \\
\text { Carará, } \\
\text { Costeiroe e } \\
\text { Igarapezinho }\end{array}$ & 565 & $17.357,00$ & Baiāo & ITERPA & 2002 \\
\hline Guajará Miri & Filhos de Zumbi & 70 & $1.123,00$ & Acará & ITERPA & 2002 \\
\hline Icatu & Icatu & 80 & $1.636,61$ & $\begin{array}{l}\text { Mocajuba e } \\
\text { Baiāo }\end{array}$ & ITERPA & 2002 \\
\hline $\begin{array}{l}\text { Santa Maria do } \\
\text { Mirindeua }\end{array}$ & $\begin{array}{c}\text { Santa Maria do } \\
\text { Mirindeua }\end{array}$ & 85 & $1.763,06$ & Moju & ITERPA & 2003 \\
\hline Santo Cristo & Santo Cristo & 52 & $1.767,04$ & Moju & ITERPA & 2003 \\
\hline Itacoă Miri & Itacoă Miri & 96 & 968,99 & Acará & ITERPA & 2003 \\
\hline Paca e Aningal & Paca e Aningal & 22 & $1.284,24$ & Viseu & INCRA & 2004 \\
\hline Bela Aurora & Bela Aurora & 32 & $2.410,28$ & $\begin{array}{c}\text { Cachoeira } \\
\text { do Piriá }\end{array}$ & INCRA & 2004 \\
\hline 17 territórios & $\begin{array}{c}41 \\
\text { comunidades }\end{array}$ & 2.159 & $54.874,04$ & & & \\
\hline
\end{tabular}

Fonte: www.iterpa.pa.gov.br, 2017.

No Quadro 01, percebe-se que perante o Governo Federal a comunidade pesquisada do Jurussaca é reconhecida como uma comunidade quilombola e se faz presente e atuante no município de Tracuateua, Nordeste Paraense. O que permite tecer uma roupagem de investigação para se perceber os saberes tradicionais na construção cultural do artesanato desta comunidade com a relação etnomatemática. Isso é possível porque o próprio espaço e cultura do povo quilombola possui sua característica particular na produção do artesanato.

Assim, o diálogo entre a produção do artesanato desenvolvido pelos jovens e adultos e a presença dos conceitos geométricos na comunidade quilombola do Jurussaca, perpassam por uma diversidade cultural que é delineada pela Educação Matemática, pesquisadas a partir de questões da Etnomatemática.

Desde o mundo antigo, a matemática passou a ser teorizada por diversos autores gregos que contribuíram para que ela viesse a se tornar ciência. Um dos principais protagonistas nessa área é o matemático grego Euclides, que organizou sua teoria para "ordenar logicamente o conhecimento geométrico" (LUNGARZO,1993, p. 07), onde apresentava as experiências vivenciadas com relação à história de vida dos camponeses do Egito, eles utilizavam técnicas de medidas geométricas para delimitar suas parcelas de terra. 
$\mathrm{Na}$ época do Renascimento e da Idade Média, os problemas matemáticos já eram resolvidos geometricamente, aparecendo assim, a entidade de novas equações, ou seja, novos números. O século XVII e XVIII apresentam um caráter mais dinâmico a ponto de não estudar somente as figuras, curvas e números, agora também as funções são presentes a essa matemática. No século XIX há uma preocupação pela fundamentação teórica da Geometria e Aritmética; o chamado "conceito de números e definições" (LUNGARZO, 1993, p.17).

De acordo com D' Ambrósio (2007), a matemática acadêmica praticamente excluiu os estudos da antropologia durante a primeira fase do século XX, desprezando assim toda diversidade cultural desta época, haja vista que não há construções de trabalhos matemáticos relacionado à cultura de uma forma geral e também na antropologia não são encontrados estudos relacionados com a matemática.

A etimologia da Etnomatemática pode ser dialogada sobre a própria área conceitual de etno que "se refere à questão do ambiente natural, social, cultural e imaginário" e "matema" significa o ato de explicar, aprender, e conhecer; "tica" relaciona os modos de estilos, artes e técnicas (D’ AMBRÓSIO, 2007, p.06). Este refinamento conceitual situa o leitor a respeito desta tendência matemática que valoriza os conhecimentos tradicionais das populações e dinamizam um ensino aplicado da matemática sobre a cultura produzida do próprio espaço. Logo, esses conceitos contribuem para entender a dinâmica do estudo sobre a Etnomatemática e sua relação com a cultura africana.

\section{Percurso metodológico}

$\mathrm{Na}$ busca da valorização dos múltiplos saberes, oriundos das diversas contribuições étnicas, enfatizando, particularmente, os saberes matemáticos usados pelos quilombolas, na principal atividade produtiva - o artesanato - foi usado como fio condutor a abordagem qualitativa do tipo fenomenológico, que segundo Chizzotti (2001) analisa os fenômenos situados em uma determinada investigação e situa o investigador sobre as trajetórias que vão se constituindo na delimitação, descrição e compreensão de um determinado objeto. Ao descrever a vivência sobre a produção do artesanato desenvolvido pelos jovens e adultos artesões e os possíveis diálogos destes saberes no contexto das duas escolas na comunidade, identificou-se a essência do fenômeno vinculada a experiência vivida por estes sujeitos.

Sob essa diretriz, inicialmente, se fez necessário o levantamento bibliográfico, que na visão de Santos (2002, p. 57), permite "a interlocução das fontes consultadas durante a investigação que definiram a posição teórica de diversos autores”. De acordo com essas fontes as informações consultadas foram correlacionadas com os saberes tradicionais e a Etnomatemática, presentes na produção do artesanato desenvolvido pelos jovens e adultos.

A partir dessa fase desenvolveu-se a pesquisa de campo, que é "um lugar onde acontecem os fatos, fenômenos e processos" (CHIZZOTTI, 2001, p.68). Nessa etapa, aconteceram as observações, um método que possui várias técnicas para serem 
aplicadas, pois trata-se de ver e registrar os fatos que acontecem na comunidade. $\mathrm{O}$ ato de observar para fins científicos significa muito mais que ver e ouvir, consiste em apreender além do que é dito, examinar as entrelinhas da fala, o comportamento, os atos - como as práticas do artesanato que servem para coleta de informações. Entre elas, optou-se pela observação participante, que possibilitou a realização natural de entrevistas, esta técnica na visão de Chizzotti (2001, p.90), "é uma comunicação entre dois interlocutores, o pesquisador e o informante, cuja finalidade deve permitir o esclarecimento das informações a serem tratadas".

Nas entrevistas, semi-estruturadas, "o sujeito pesquisado pode efetuar o seu discurso livre, sendo orientado pelo pesquisador por algumas palavras - chaves" (Chizzotti, 2001, p.95), privilegiou-se as informações que continham história de vida dos envolvidos, as práticas tradicionais com a produção do artesanato e as atividades das professoras organizadas no contexto da sala de aula, isto possibilitou perceber os conhecimentos tradicionais para o uso das figuras geométricas planas e as possíveis articulações ou não das atividades construídas pelas professoras a respeito dos conhecimentos matemáticos tradicionais para as crianças na comunidade do Jurussaca. As entrevistas foram operacionalizadas entre o período de agosto de 2016 e março de 2017.

Assim, para realização deste estudo, elegeu-se, no universo da comunidade, trabalhar com 13 moradores artesões, que são os pais das crianças que estudam nas duas escolas, dentre eles $(=08)$ moradores mais antigos que possuem saberes tradicionais matemáticos acumulados de geração a geração e $(=05)$ jovens que estão aprendendo as práticas tradicionais do artesanato com os moradores mais antigos. Além de (=02) professores que atuam na escola da comunidade, uma professora que atua na turma de $1 \% / 9$ e 2\%/9 na E.M.E.F. Raimundo Antonino de Araújo e a outra professora que trabalha com 3\%/9 e 4\%/9 na E.M.E.F. Ludovino Antônio de Araújo, ambas desenvolvem suas atividades no turno da manhã e da tarde. As entrevistas com as duas professoras foram importantes para saber se no cotidiano escolar está havendo um diálogo entre os professores, os pais e alunos no que se refere aos saberes tradicionais matemáticos desenvolvidos na construção dos artefatos desta comunidade quilombola com o contexto da sala de aula. Para Freire (1996), o diálogo é um fenômeno da existência humana que se intercruza pela palavra, pela ação e reflexão que propiciam a transformação do homem no mundo.

Outra técnica de coleta de dados utilizada foram as fotografias. Para Kossoy (1989), a fotografia é um registro que não se reduz aos aspectos visíveis das imagens, pois requer um esforço de interpretação que resulta de um empenho representativo sobre uma determinada realidade e seus valores simbólicos. Logo, as fotografias expressaram o registro visual das vivências, sentidos e significados dos sujeitos pertencentes as suas experiências, desde a retirada das plantas (guarumã e coco de babaçu), ao processo de confecção dos artefatos culturais, presente tanto na pesca artesanal quanto na agricultura familiar, utilizados no cofo, no paneiro e o socó.

É preciso deixar claro que as falas dos sujeitos, moradores artesões e das professoras, foram transcritas e analisadas fidedignamente no sentido de manter os saberes tradicionais que circulam na comunidade e as experiências das professoras na escola, bem como elencou-se pseudônimos em suas identificações para manter a conduta ética dos sujeitos entrevistados neste estudo. 


\section{Análise dos dados}

Para compreender os saberes tradicionais na produção do artesanato desenvolvidos pelos jovens e adultos quilombolas e os conceitos geométricos na comunidade do Jurussaca, fez-se necessário resgatar a origem dessa comunidade para perceber as influências ocorridas na formação dessa população:

Agente se esquece de muita coisa, a origem foram 03 pessoas que eram africanos e vieram do Maranhão é dos Araújos da família do finado Zé Retiro, da Dona Bibi era minha mãe. Ela era mãe da Virturina; mãe da Joana - todos da família Araújo - são de raízes, daí surgiu o nome de Jurussaca (ARTESÃO, B. M. C, 2016).

A importância dessa fala é que permite tecer a origem do quilombo do Jurussaca no Nordeste Paraense. A comunidade possui traços culturais de quilombos muito claro como estrutura física das residências, atividades de subsistência (agricultura pesca artesanal e as manifestações culturais que os identificam como quilombolas).

Figura 01: moradias da comunidade

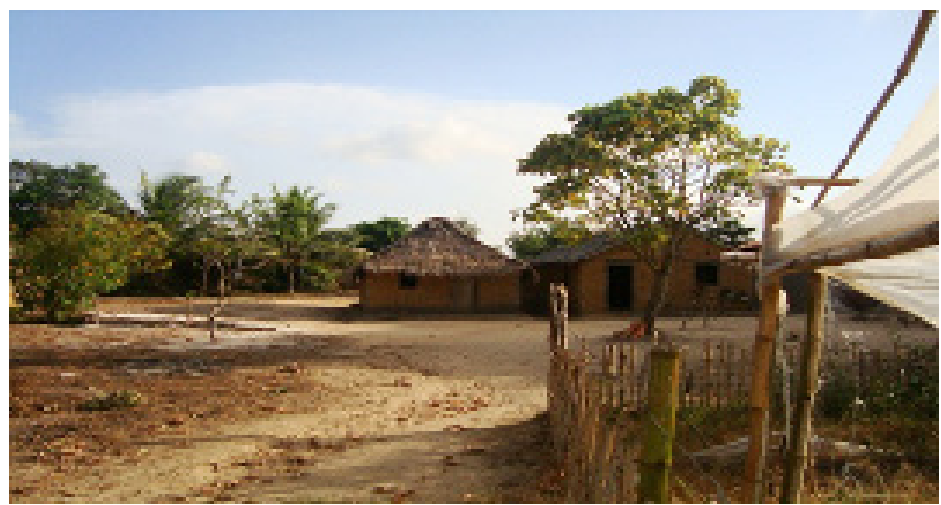

Fonte: Acervo dos autores, 2016

Segundo o presidente da comunidade, a localidade é constituída por:

(...) 78 famílias mais ou menos, eu fiz um primeiro levantamento no início do ano passado tinha na comunidade 559 pessoas. Sobre as casas temos 59 no total, sendo que o INCRA nos deu 59 casas no total, dando uma média de 110 a 120 pessoas nessas casas do INCRA. Nem todos possuem ainda essas casas do INCRA. Presidente da comunidade (ARTESÃO, V.R.R. A/PRESIDENTE DA COMUNIDADE, 2016).

Constata-se uma diferença no levantamento feito pelo presidente da comunidade, quando declara que a contagem no início do ano de 2016 resultou aproximadamente em 78 famílias, constando 559 pessoas, e, a contagem apresentada no quadro 01, $3^{\text {a }}$ coluna, onde é apresentado os dados do ITERPA sobre algumas comunidades 
quilombolas do Estado do Pará, em 2002, foi de 45 famílias, isto explica o porque, na fala do presidente, "nem todos possuem essas casas do INCRA", houve um crescimento significativo do número de moradores residentes nesta comunidade.

Com relação à Educação, a comunidade é um espaço que necessita de uma educação voltada para o homem do e no campo, respeitando-lhe o ensino obrigatório de História e Cultura Afro-brasileira (Lei 10.639/03).

Baseado nisso, a própria Lei de Diretrizes e Bases da Educação 9394/96 (LDB), articula que "Todo cidadão tem direito e acesso à escola". A necessidade de formação de turmas para crianças, jovens e adultos é uma prática pedagógica que deve se fazer presente na comunidade, uma vez que passa pela compreensão de análise do estudo da memória da população e consequentemente dos saberes construídos na comunidade. Mas a realidade é outra, pois:

\begin{abstract}
A falta de interesse de nossos governantes parece que não querem enxergar, pois sabemos que devemos ter uma atenção especial por sermos uma comunidade quilombola, mas não sabemos como questionar nossos direitos (ARTESÃO, B.M. L, 2016).

Já teve turmas de Educação de Jovens e Adultos de $1^{\mathrm{a}}$ e $2^{\mathrm{a}}$ etapa pra cá, só que nunca mais veio turmas da EJA e tem muita gente que precisam estudar, agora tem duas turmas do Ensino Fundamental para crianças nas escolas da comunidade (ARTESÃO, V.R.R.A, PRESIDENTE DA COMUNIDADE/2016).
\end{abstract}

Essa é outra constatação, que precisa ser questionada como uma política educacional junto ao município, para atender os direitos dos quilombolas no que diz respeito a ofertas de turmas da Educação de Jovens e Adultos, garantidos na LDB, 9394/96, pois mesmo com o funcionamento de duas turmas do Ensino Fundamental de Nove Anos, os jovens e adultos estão sem estudar devido o próprio município não ofertar turmas da EJA na comunidade.

Segundo a LDB 9394/96, a Educação de Jovens e Adultos - EJA é uma modalidade de ensino da Educação Básica que precisa garantir os direitos dos destes sujeitos pelas suas experiências de vida. A EJA foi constituída para compensar aos jovens e adultos as oportunidades que não lhes foram dadas de estudar em suas respectivas épocas vividas. E isto vem acontecendo na comunidade do Jurussaca, pois mesmo obtendo demandas de sujeitos para estudar, seus direitos estão sendo negados quando há uma ausência de formação de turmas da EJA na comunidade, o que indica processos de exclusão aos jovens e adultos quilombolas do Jurussaca.

Para Freire (2001), os saberes, as histórias e as memórias constituídas pelos jovens e adultos são a base para a produção do conhecimento nas instituições educativas. Na comunidade, além dos moradores antigos, existem muitos jovens que não se alfabetizaram; e eles são os que possuem o conhecimento transmitido pela população mais idosa, sobre a montagem dos produtos artesanais, que são utilizados para produção agrícola e na pesca artesanal. 
Os produtos artesanais produzidos pelos jovens e adultos, na comunidade, são advindos do manuseio das plantas de guarumã, coco de babaçu (figuras 2 e 3 ) e buriti.

Figura 02: Guarumã

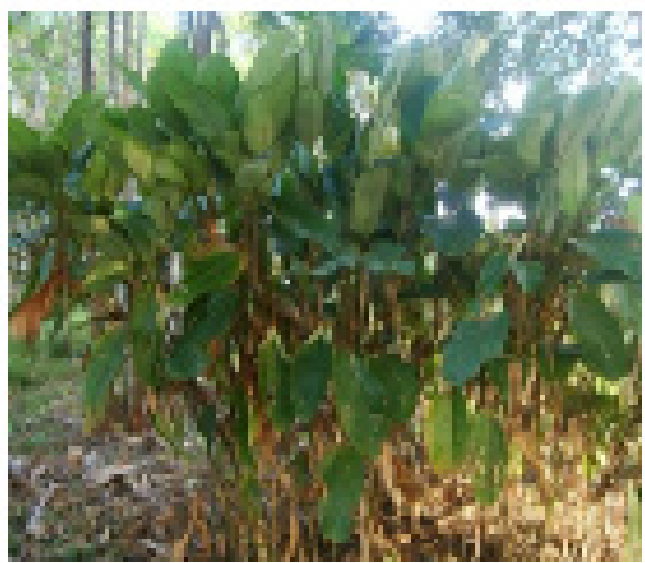

Fonte: Acervo dos autores, 2016

Figura 03: Coco de Babaçu

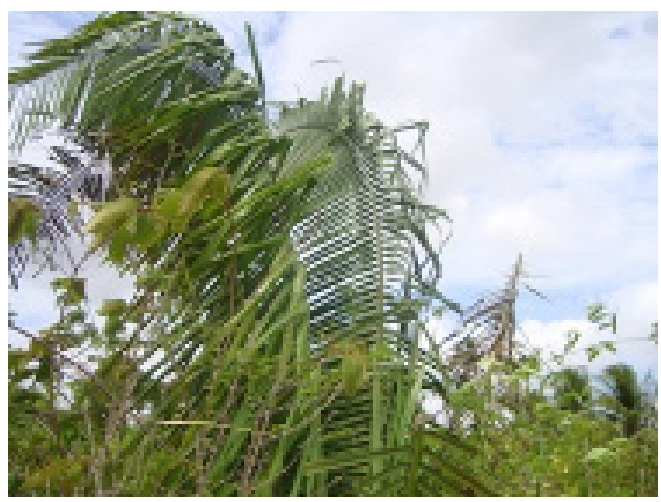

Fonte: Acervo dos autores, 2016

A relação da comunidade com as plantas é intensa, pois todo material usado para produção (guarumã, coco de babaçu, buriti e outros) são retirados da mata, preocupando-se com o manejo dessas plantas, estabelecendo assim uma relação de sustentabilidade entre os membros da comunidade e o ecossistema.

Sobre a atividade produtiva, a comunidade se ocupa com agricultura, pesca e artesanato, para subsistência e venda. 
Eu trabalho na agricultura com mandioca, feijão, milho, alguns trabalham com arroz, com algumas plantas que a gente também produz paneiros e chapéus (ARTESÄO, J. K. M, 2016).

A prática produtiva no cotidiano da comunidade permite levantar a identidade do lugar, espaço e cultura da população quilombola. Isso porque durante a atividade produtiva há uma construção dos materiais artesanais para atender as necessidades dessa população, tanto para a pesca artesanal quanto para a agricultura familiar.

Para Castro (1997), o valor dos saberes tradicionais, expressam diversos sentidos, significados e instrução de conhecimento adquirido ou repassado para a construção dos valores que são atribuídos de geração a geração nas comunidades locais. Quanto a produção do artesanato os trabalhadores apresentaram uma variação de materiais produzidos que:

Todos fazem tanto homens quanto mulheres, primeiro para colocar mandioca, paneiro de filho para pegar peixe, paneiro serão para botar carga no cavalo/ chapéu estilo boné, e redondo/ tem a peneira/ abano de palha de guarumã. Falta força de vontade e organização e incentivo do município para ajudar a gente, não tem a pessoa para ajudar - o local de direção para repassar para outra pessoa e revender (ARTESÃO, B.M. L, 2016).

Essa relação de gênero fortalece a produção das famílias que residem no quilombo, sobre o artesanato, o que permite identificar que a relação de aprendizagem também acontece em casa entre mulheres, jovens e adultos. As realidades apresentadas culturalmente nas comunidades passam por um quadro de percepções que apresentam constantes reproduções de saberes e práticas tradicionais.

A maioria de quem produz o artesanato são os jovens e adultos, eu venho correndo atrás das coisas para a comunidade. A dificuldade para montar e saber a história, a história foi muito difícil; não tinha uma pessoa de frente eu quando criança eu ouvia os meus tios, avós, amigos e eu ficava ouvindo aquilo que ficava na minha memória, eu me interessava e aí eu fui botando na cabeça com os conhecimentos dos antepassados a gente tá buscando recursos (ARTESÃO, J.K.M, 2016).

Nesse embate o entendimento dessas relações e reproduções de saberes dos povos tradicionais exige um esforço no sentido de lembrar as práticas dos saberes, entre eles o matemático, que os povos possuem de acordo com a sua representação social na localidade, por isto as memórias e ensinamentos dos moradores mais antigos aos jovens são fundamentais para que não se perca os conhecimentos tradicionais quilombolas.

Outra constatação importante é que mesmo com a ausência de apoio por parte do município para ajudar a comunidade quilombola tanto no âmbito da oferta de turmas da EJA quanto na organização da comunidade para o incentivo do trabalho cooperativo, os próprios quilombolas vem buscando se organizar em cooperativas, tanto mulheres e homens, para buscar recursos do governo no sentido de permanecer sua cultura, acreditar no seu fazer e propiciar o desenvolvimento da comunidade. 
O reconhecimento sobre os saberes e práticas tradicionais, considera pensar criticamente entre os sujeitos das comunidades, ou seja, suas questões emergentes na sociedade, pelos sujeitos e seus territórios (FREIRE, 2001).

Neste sentido é importante mencionar a percepção de alguns membros da comunidade que produzem o artesanato, levando em consideração o passo a passo dessa construção (Figuras 04 a 07), o valor e a utilização de cada um deles.

Figura 04: Retirada da folha

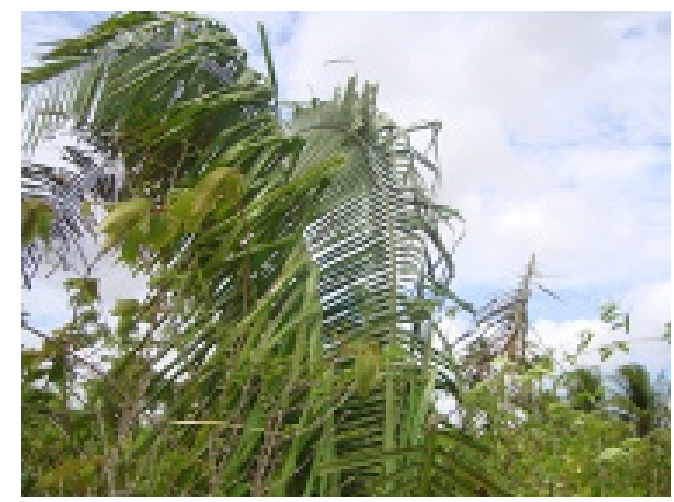

Fonte: Acervo dos autores, 2016

Figura 05: Confecção inicial da produção

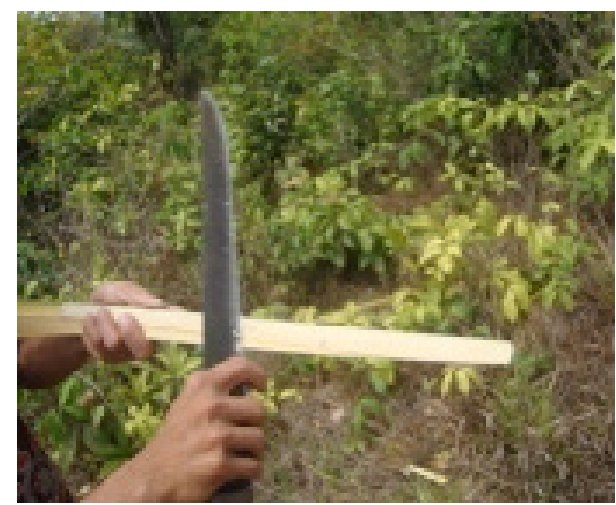

Fonte: Acervo dos autores, 2016 
Figura 06: Manutenção das folhas

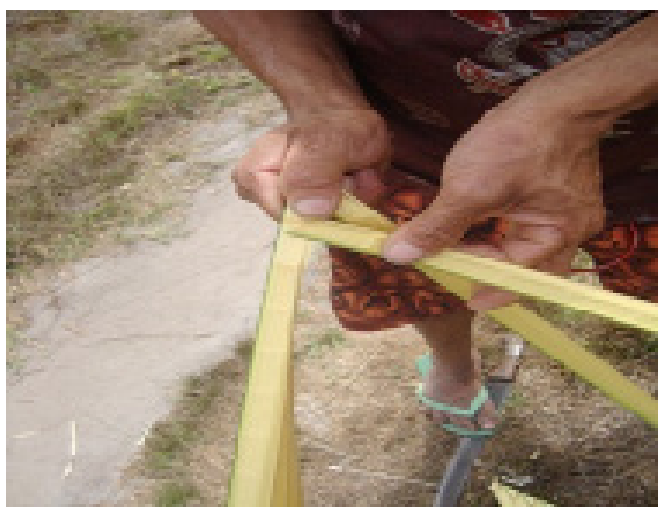

Fonte: Acervo dos autores, 2016

Figura 07: Organização da tecelagem do cofo

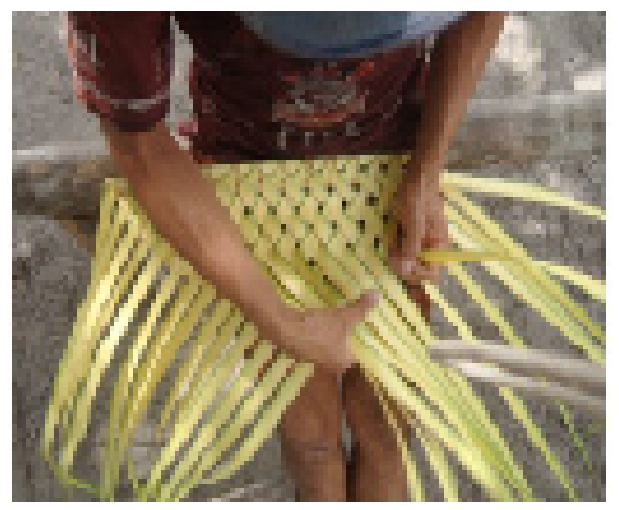

Fonte: Acervo dos autores, 2016

As figuras acima indicam que os saberes tradicionais perpassam pela lógica de todo um processo para a construção deste artefato cultural:

"A folha do coco de babaçu, não serve, a gente tem que tirar o olho do coco de babaçu, depois racha ao meio esta folha e começa limpar tirando o bucho, depois tece ele quebrando as folhas do talo em duas partes que foram quebradas e uni um talo sobre o outro e começa a faze a armação com as folhas do talo, ao final na parte do fundo é que finaliza a armação do cofo. O valor do cofo custa em média de R\$1 a 5,00 reais (ARTESÃO, S.S, 2016).

Nesta fala, observa-se, que de acordo com as figuras (4 a 7), o processo de construção do cofo (figura 06) apresenta-se o ponto onde começa ser tecido da folha do coco de babaçu, em seguida acontece um corte pelo vértice formando um ângulo (figura 06), que ao ser medido (figura 07) apresenta um formato do triângulo; mantido na tecelagem, até formar o retângulo, que é representado pela figura do cofo. 
Figura 08: Produção final: o cofo que planificado apresenta o retângulo
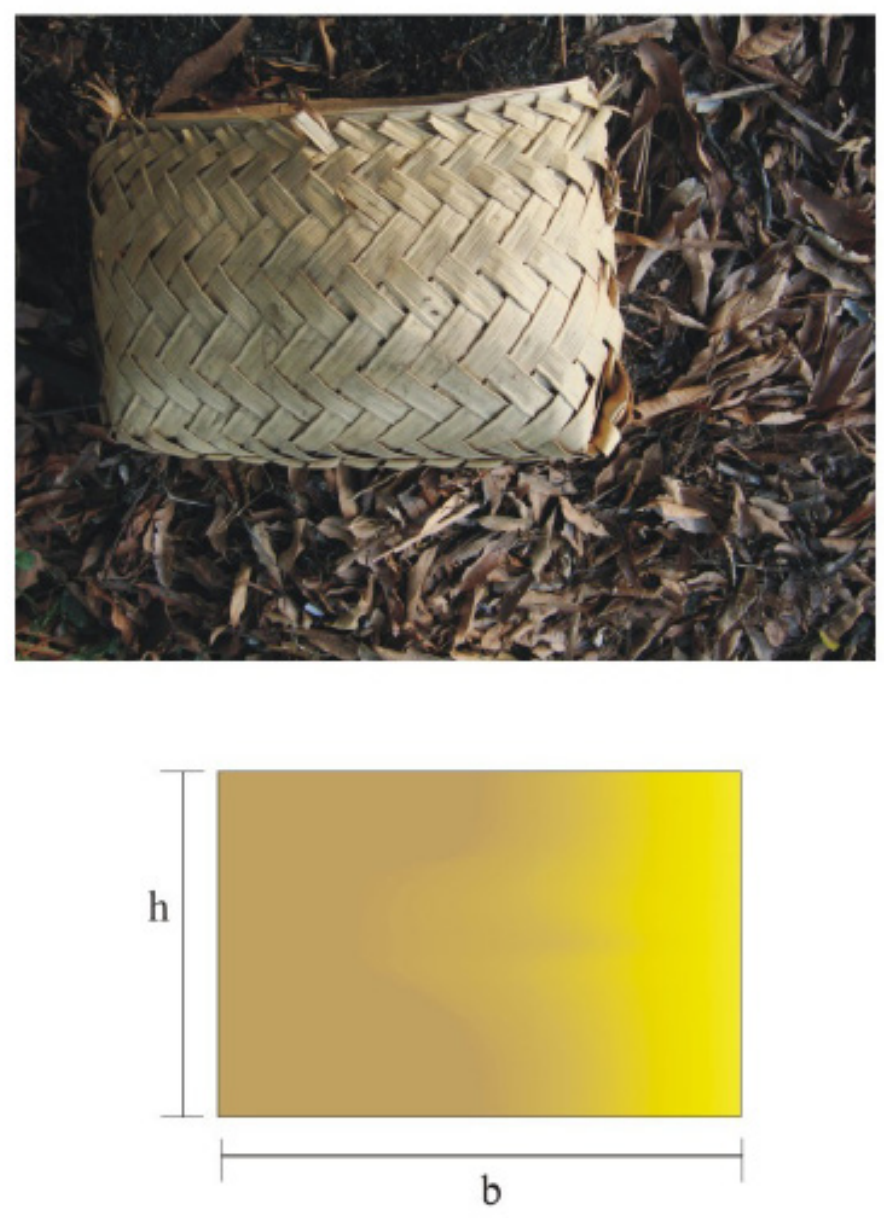

\section{Retângulo}

Área do Retângulo $=b \times h$

Fonte: Acervo dos autores, 2016

Sobre a utilização do cofo o artesão ressalta:

"O Cofo é utilizado para guardar, peixe, caranguejo, camarão e as vezes em época de colheita do feijão caupi, os agricultores retiram as várzeas e colocam o feijão dentro do cofo, este material é conhecido como a bolsa do agricultor" (ARTESÃO, M.J.C, 2016).

O cofo considerado como "a bolsa do agricultor", o torna mais que um simples objeto construído, representa a identificação da cultura quilombola, que no processo de construção, traz os conhecimentos etnomatemáticos, pelo viés dos con- 
ceitos geométricos. Na visão de Castro (1997), é necessário que ao estudar as sociedades tradicionais, deve-se demonstrar que o ato de pescar, caçar e plantar se manifesta socialmente a cada grupo em uma cadeia de sociabilidade grupal, responsáveis pela integração da identidade cultural de cada técnica construída por uma população, seja ela indígena, pescadora, seringueira, castanheiros ou quilombolas.

Isso é constatado nas demais construções dos produtos artesanais, como o paneiro de guarumã. O paneiro de guarumã segundo o morador B.G. é usado para "tudo até para colocar o feijão caupi", segue os seguintes passos (Figuras 09 a 12), na construção que foi realizada gentilmente em miniatura, pelo artesão, exclusivamente para este trabalho:

Tira-se o varão da planta do guarumã, racha a tala em quatro quartos, depois tira o bucho e faz uma quebra na ponta da tala para destalar o guarumã e fazer a armação; coloca o pé direito para firmar e começar a fazer o fundo do paneiro; começa por um olho onde agente atravessa de duas em duas talas sempre colocando o pé para fazer armação. A medida que a gente vai colocando as talas se divide ao meio para ficar certo a montagem dos olhos do paneiro. Existem dois tipos de paneiro, o de olho com um buraco pequeno, como a gente chama e o de urana que é o paneiro de buraco maior (ARTESÂO DA COMUNIDADE, B.G, 2016).

Diferentemente do cofo, o paneiro de guarumã apresenta um ponto onde é tecido (figura. 09) com a tala do guarumã, à medida que se vai retirando o bucho as talas vão se entrelaçando até serem firmadas com outra tala que visualiza um pentágono, (figura 11) se redimensionando até formar o paneiro que apresenta a seguinte figura:

Figura 09: Vara de guarumã.

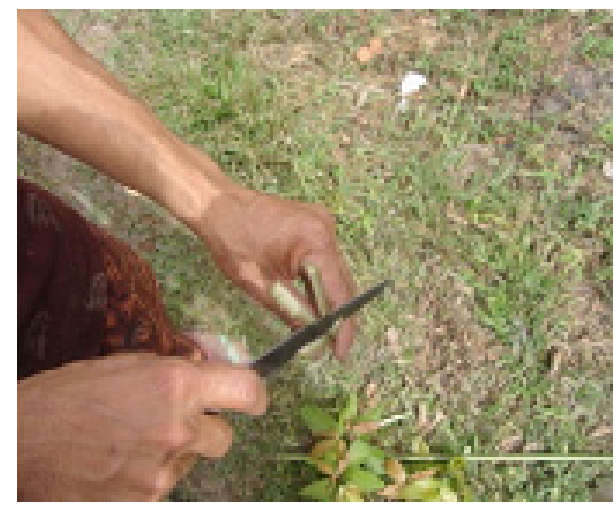

Fonte: Acervo dos autores, 2016 
Saberes tradicionais de jovens e adultos e a presença de conceitos geométricos em Tracuateua/PA

Figura 10: Retirada do bucho do guarumã

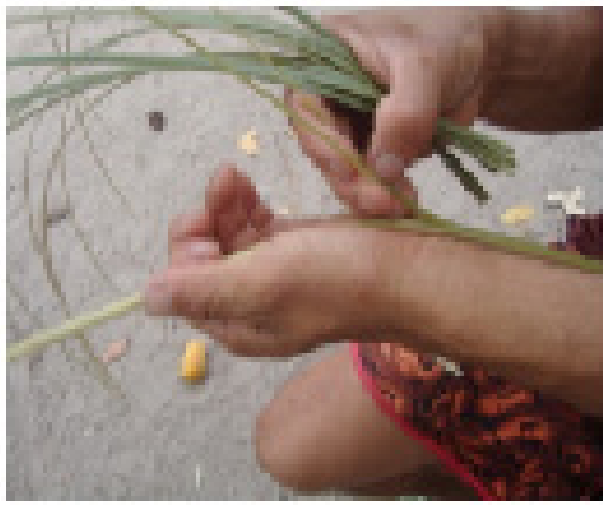

Fonte: Acervo dos autores, 2016

Figura 11: Fundo do paneiro de guarumã

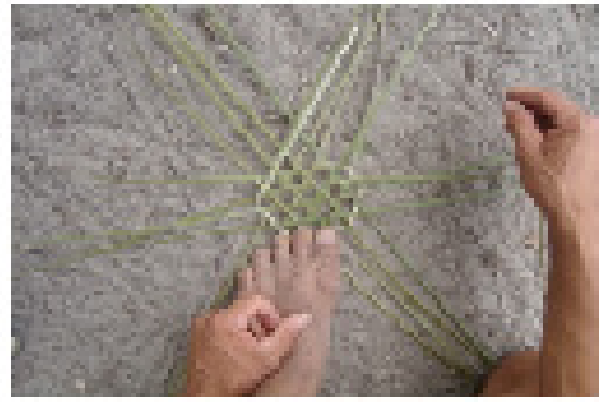

Fonte: Acervo dos autores, 2016

Figura 12: Tecelagem do paneiro

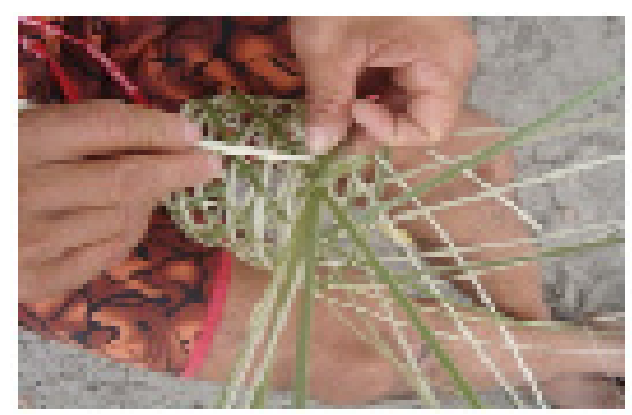

Fonte: Acervo dos autores, 2016 
Quando montado, o paneiro de guarumã (Figura 13), apresenta as figuras geométrica planificada: circunferência e o retângulo:

Figura 13: Paneiro de guarumã representando as figuras geométricas planas

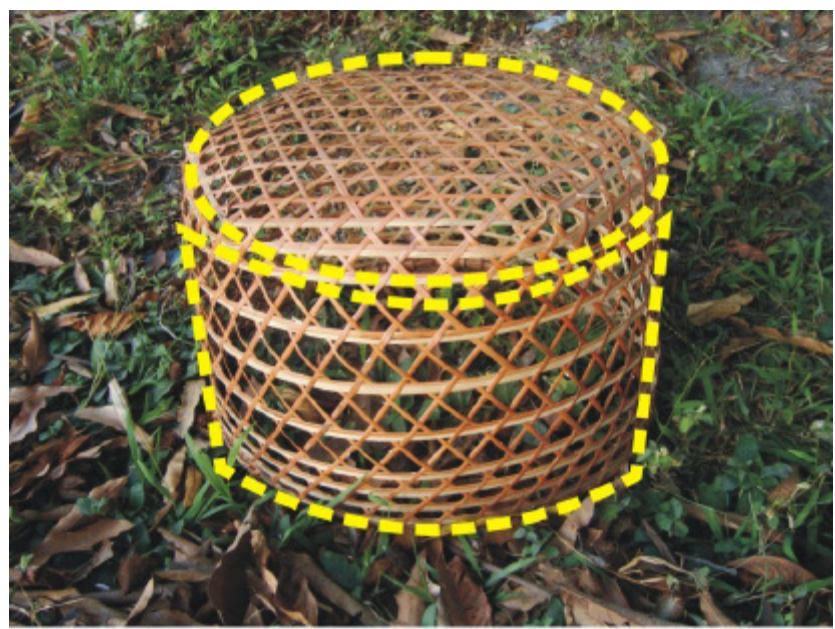

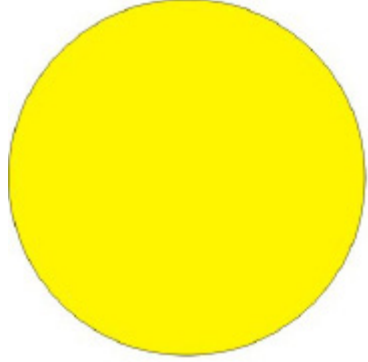

Circunferência

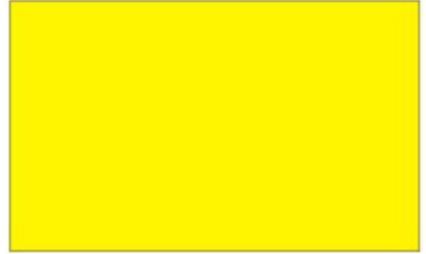

Retângulo

Área do Retângulo $=b \times h$

Área da Circunferência $=\pi r^{2}$

Fonte: Acervo dos autores, 2016

Estas figuras geométricas, circunferência e retângulo, devem servir de base para a construção de um currículo crítico e emancipatório que podem ser visualizados nos seus saberes e práticas tradicionais do cotidiano. A escola da comunidade, infelizmente, não efetua este exercício com as crianças, e não dialoga com os jovens e adultos sobre os seus saberes matemáticos, transmitidos de geração a geração, isto foi perceptível quando se entrevistou as professoras no cotidiano escolar

Outro produto artesanal, no qual se percebe os conceitos geométricos - e mais difícil de construir - é o socó.

O socó serve para gente pegar peixe, traíra e outros peixes por aqui. As vezes as pessoas das outras comunidades vem pedir pra gente e a gente empresta mas eles esquecem de devolver. O socó é muito 
difícil de fazer. Primeiro a gente tira as varas do mato ou tinta com alguns chamam, depois raspa com uma faca os pauzinhos e faz a pontinha das varas. Aí a gente pega um arame e faz uma roda do socó que vai ser para tecer na base as varas são amarradas, na roda do arame arrematando com o soro (fios). Depois que tiver armado a base com arame a gente amarra o fio no meio e na ponta passando um pelo outro pra ficar mais forte o socó. Aí se pega o soro (fio) e vai passando na cabeça do socó, na ponta (boca do socó) tem que ficar entremeado duas varas em cima e uma embaixo, duas em cima e uma embaixo, na direção e medida de um braço. O socó é um dos materiais que dá mais trabalho pra gente fazer. Um socó novo custa uns $\mathrm{R} \$ 25,00$ (ARTESÕES DA COMUNIDADE, 2016).

Quando retirado da mata, o agricultor também forma um ponto para raspar o talo até apresentar uma espessura exata para o encaixe das talas no arame ou fio. Esse material leva muito tempo para ser construído, pois o grau de dificuldade é muito maior quando relacionado ao cofo e ao paneiro. Considerado muito importante, para a pesca artesanal, esse instrumento é construído da seguinte forma (Figuras 14 a 15).

Figura 14: Raspagem das varas

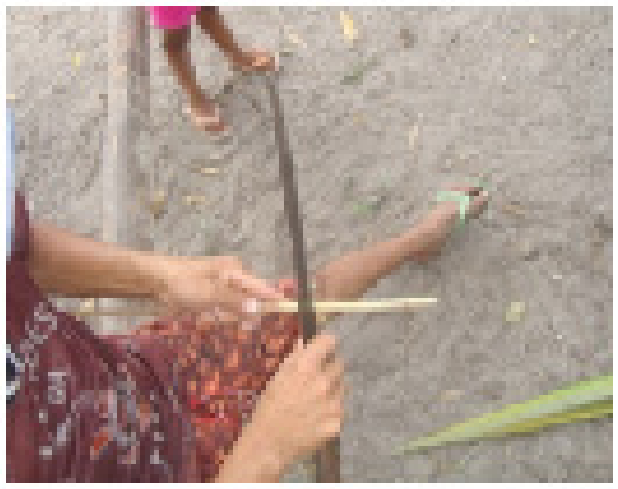

Fonte: Acervo dos autores, 2016

Figura 15: Fio na cabeça do socó

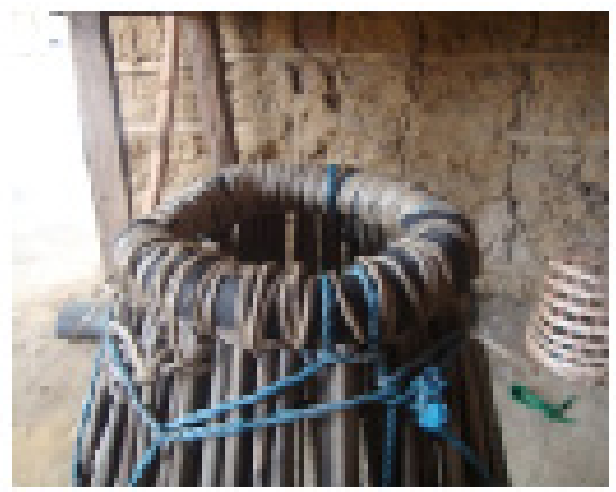

Fonte: Acervo dos autores, 2016 
O socó, quando pronto, tem a forma de um cone, mas quando planificado remete as figuras de um triângulo, trapézio e a semicircunferência.

Figura 16: Socó Planificado
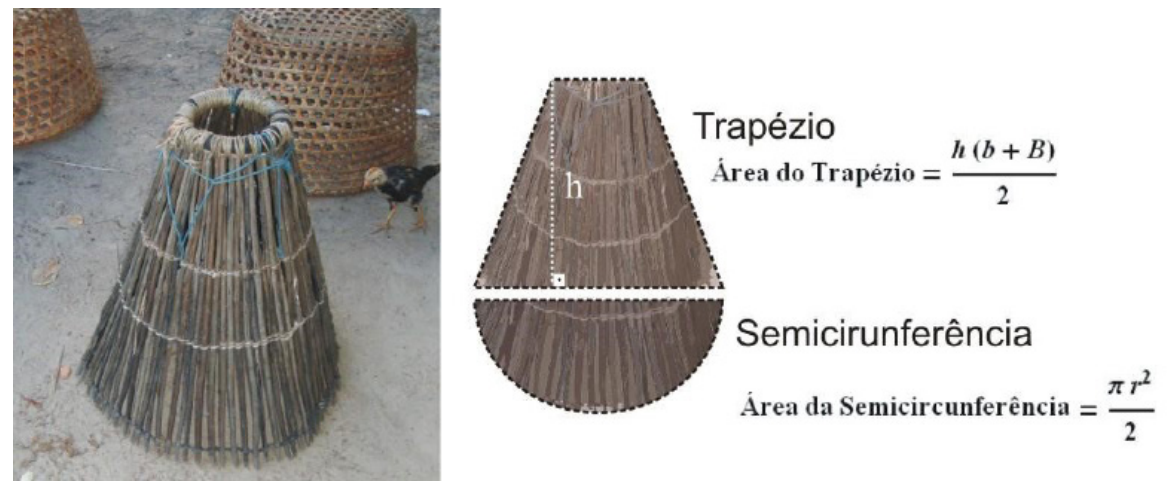

Fonte: Acervo dos autores, 2016

Todo esse conhecimento etnomatemático, que vem atravessando gerações na produção de artesanatos, é ignorado pela escola, segundo os moradores:

Existem duas escola aqui na comunidade uma de $1^{\mathrm{a}}$ e $2^{\mathrm{a}}$ série a outra de $3^{\mathrm{a}}$ e $4^{\mathrm{a}}$ série, na comunidade do cebola, mas a professora não ensina isso. Eu vejo o caderno do meu filho e não tem a presença de reconhecer essa figuras aí (MORADORA, J. K. M, 2016).

$\mathrm{Na}$ comunidade há duas escolas de ensino regulares e os pais não reconhecem nas aulas ministradas pelas professoras os conhecimentos desenvolvidos na comunidade, isto acontece porque os pais precisam, para além de olhar o cadernos de atividades dos seus filhos, dialogarem com as professoras, estes pais são os jovens e adultos que confeccionam os artefatos culturais, eles podem mobilizar uma ação coletiva com as professoras para desenvolverem a confecção dos produtos no interior das duas escolas com as crianças. De acordo com Freire (1996), por meio do diálogo o homem reconhece o seu semelhante, este se solidariza com outrem e não estabelece uma relação de dominação, pois o reconhecimento do outro perpassa pela valorização da diversidade de sujeitos que produzem saberes em suas práticas de trabalho nas comunidades, na religiosidade, na busca dos seus direitos e deveres, na relação com a natureza, na articulação dos saberes tradicionais com os saberes escolares, rompendo com uma educação que deposita os conhecimentos aos alunos que ainda se faz presente no interior das escolas.

Mas atualmente isso não vem acontecendo, e é reforçado por outros moradores quando dizem:

A professora nunca chamou agente para fazer material e ensinar essa geometria plana (MORADOR, B. M. T, 2016). 
Essa afirmação mostra o distanciamento entre a escola e a realidade dos alunos, na qual a escola necessita do trabalho coletivo com os pais para desenvolver os saberes tradicionais da comunidade quilombola e seus costumes. Isto é presente na seguinte fala:

Rapaz a professora não trabalha isso não, sabe que eu não tinha pensado sobre montar uma turma para produzir esses materiais e revender, em Bragança e também não tinha pensado sobre que a gente já pratica a matemática quando fazemos a medição da construção dos chapéus, bonés, paneiro, cofo, estamos utilizando a matemática (sic. PRESIDENTE DA COMUNIDADE, 2016).

Logo, os moradores da comunidade precisam se mobilizar por meio de algumas ações: criar estratégias para produzir e revender seus produtos artesanais em outros municípios; reconhecer a presença dos conhecimentos geométricos no artesanato e dialogar com as professoras para desenvolver os saberes matemáticos com as crianças no cotidiano da escola, pois a produção artesanal é a principal característica dos quilombolas de Jurussaca, em Tracuateua- Pará.

$\mathrm{Na}$ realização das entrevistas com as duas professoras para saber as possíveis articulações do conhecimento matemático formal com os saberes tradicionais, obtevese as seguintes falas:

Como as crianças são pequenas, eu trabalho com algumas noções dessas figuras geométricas por meio dos livros, mas não tem como me aprofundar porque ainda vejo isto sendo difícil para elas que são do $1 \% / 9$ e $2 \% / 9$, eu não tinha pensado em fazer isto com o artesanato daqui da comunidade (PROFESSORA, A.S.M, 2017).

Eu nunca tinha pensado nisso! Vejo os moradores daqui fazendo estes abanos, chapéus, paneiros, mas nunca me passou pela cabeça que podemos desenvolver isto com as crianças daqui da escola. Eu faço isto com os objetos pra eles terem noção das figuras geométricas. Acho que é uma excelente ideia para pensarmos com estes moradores daqui (PROFESSORA, B.Y.Z, 2017).

Observa-se na fala das professoras que não há uma associação dos saberes tradicionais matemáticos desenvolvidos pelos jovens e adultos artesões com suas práticas no cotidiano da escola, elas trabalham com noções de figuras geométricas mediados por livros e objetos. Contudo, reconheceram a importância de desenvolver este trabalho com as crianças, o que demarca a necessidade do diálogo entre os sujeitos que constituem o entorno desta comunidade. Portanto, para que isto ocorra é preciso do diálogo, segundo Freire (1996), este só possui sentido quando há uma ação e reflexão sobre a realidade em que os sujeitos estão inseridos, uma conquista implícita dos sujeitos dialógicos - de criação e resistência - que rompem com um ato de que os saberes eurocêntricos, depositados na ideia de um sujeito no outro, são os únicos saberes válidos na sociedade capitalista.

Os saberes constituídos pelas populações tradicionais são invisibilizados pelo discurso da sociedade moderna, e esta invisibilização dos saberes tradicionais que é criticada por Freire (1996), pois estes saberes possuem uma diversidade de conhecimentos o qual devem ser problematizado no contexto local, cuja intenção é torná-los, 
por meio de sua produção sociais, ambientais, culturais, em saberes científicos. Logo, os saberes das populações tradicionais, podem ser dialogados como forma de produção do conhecimento para e com a escola, e isto se torna mais significativo para os educandos e educadores, inclusive na comunidade do Jurussaca pela produção do conhecimento matemático do artesanato no contexto escolar.

\section{Tecendo algumas considerações}

A busca pelo conhecimento matemático dos quilombolas, na Comunidade Jurussaca, em Tracuateua, no Nordeste Paraense, demonstrou a importância desses saberes na vida da população agro pesqueira e artesanal, até os dias atuais. O cálculo do tamanho e largura dos cofos, paneiros e socós eram cuidadosamente baseados em conceitos geométricos, embora o produtor não tivesse essa noção. Sabia que deveria iniciar de um determinado ponto, fazendo abertura para tecer, formando figuras, e daí prosseguir até o final do trabalho. Com isso obtém um objeto firme, forte e seguro, capaz de suportar o peso de outros produtos. A percepção desse processo remete ao valor dado sobre os conceitos geométricos presente na produção do artesanato desta comunidade.

Neste caso, em Jurussaca, constatou-se a importância de um saber tradicional, guardado e transmitido de geração a geração, que permitiu a sobrevivência de uma população, na adversidade social em que viveu e ainda vive. Verificou-se o domínio do processo da construção dos objetos, partindo dos mais simples (o cofo), passando pelo paneiro, até chegar ao socó, que apresenta maior grau de dificuldade na tecelagem.

Essa dificuldade, dominada lentamente pelo artesão aprendiz, é respeitada, tanto por quem aprende quanto por aquele que ensina, demonstrando a sabedoria da espera da maturação dos domínios, para aquisição de outro saber. Embora esse saber, faça parte do cotidiano, na comunidade a sistematização historicamente formal a que foi investida o conhecimento, ainda é desconhecido no cotidiano da escola.

A percepção dessa realidade provoca a inquietação para a necessidade de um novo olhar aos saberes tradicionais, a fim de, a partir deles, procurar enfatizar uma educação formal com intervenções locais acerca dos conhecimentos matemáticos dos quilombolas. É importante que os pesquisadores sejam mediadores de estratégias entre os professores e moradores artesões que atuam nessas comunidades para que seja feita associações entre o saber tradicional, o fazer e o conhecer.

Neste sentido, tanto os professores como os jovens e adultos artesões não conseguem efetuar uma associação dos conhecimentos matemáticos constituído na produção do artesanato. Contudo, reconheceram a importância do diálogo entre eles para desenvolver uma produção do conhecimento matemático, por meio dos saberes tradicionais do artesanato, para as crianças do Jurussaca no contexto da sala de aula. 


\section{Referências}

BRASIL. Lei Federal no 9.394, de 20 de Dezembro de 1996. Lei de Diretrizes e Bases da Educação Nacional. Diário Oficial da União. Brasília, DF,24 dez.1996.Seção1, p.27-833. Disponível em: <http://www.planalto.gov.br/ccivil_03/leis/L9394.htm> Acesso em: 31 out. 2015.

BRASIL. Lei Federal no 10.639, de 09 de Janeiro de 2003. Altera a Lei n.o 9.394, de 20 de dezembro de 1996 (estabelece as diretrizes e bases da educação nacional, para incluir no currículo oficial da rede de ensino a obrigatoriedade da temática história e cultura afro-brasileira, e dá outras providências). Diário oficial da República Federativa do Brasil. Brasília, DF, nove, jan. 2003. Disponível em: <http://www.planalto_gov.br/ccivil_03/leis/2003/10639.hmz>. Acesso em: 31 out. 2017.

CARVALHO, J. J. de. Conhecimentos tradicionais no Brasil e na América Latina: uma agenda de resistência e criatividade. 2017. Disponível em: <http://conhecimentostradicionais.blogspot.com.br/2007/06/texto-de-referencia.html>. Acesso em: 28. Out. 2017.

CASTRO, Edna. Território, biodiversidade e saberes de populações tradicionais In: CASTRO, Edna; PINTON, F. (org.) Faces do Trópico Úmido: Conceitos e novas questões sobre desenvolvimento e meio ambiente. Belém: CEJUP, NAEA, 1997, p. 221-243.

CHIZZOTTI, A. Pesquisa qualitativa em ciências humanas e sociais/ 5. ed. São Paulo: Cortez, 2001.

COMISSÃO PRÓ-ÍNDIO DE SÃO PAULO. Comunidades Quilombolas. 2016. Disponível em: <http://www.cpisp.org.br/acoes/html/i_creditos.html. <http://www.cpisp.org.br/terras/ asp/terras_tabela.aspx.2016>. Acesso em: 29 Out. 2017.

D’AMBRÓSIO, Ubiratan. Etnomatemática: Elo entre as tradições e a modernidade - 2. ed. Belo Horizonte: Autêntica, 2007.

FREIRE, P. Pedagogia da autonomia: saberes necessários à prática educativa. 27. ed. Rio de Janeiro: Paz e Terra, 1996.

FREIRE, P. Política e Educação: ensaios Paulo Freire- 5a ed. São Paulo, Cortez, 2001.

INSTITUTO DE TERRAS DO PARÁ - (ITERPA). Pará é referência na demarcação de terras quilombolas no Brasil. Disponível em: <http://www.iterpa.pa.gov.br/noticia/par\%C3\%A1-\%C3\%A9-refer\%C3\%AAncia-na-demarca\%C3\%A7\%C3\%A3o-de-terras-quilombolas-no-brasil>. Acesso em: 30 out. 2017.

KOSSOY, B. História e Fotografia. 2.ed.São Paulo, Ateliê Editorial, 1989.

LUNGARZO, Carlos. O que é matemática? 2. ed. São Paulo. Editora: Brasiliense, 1993.

SANTOS, A. R. Metodologia Científica: A construção do conhecimento/. 5. ed. revisada; Rio de Janeiro, 2002.

SCHMITT, Alessandra; TURATTI, Maria Cecília Manzoli; CARVALHO, Maria Celina Pereira de. A atualização do conceito de quilombo: Identidade e território nas definições teóricas. Ambiente \& sociedade, ano V, n. 10, set. 2002. Disponível em: <http://www.scielo.br/pdf/asoc/ n10/16889>. Acesso em: 29 out. 2017.

* Doutorando em Educação pela Universidade Federal do Pará, Bragança, Pará, Brasil.

** Professora doutora da Universidade Federal do Pará, Bragança, Pará, Brasil. 
Rogerio Andrade Maciel - Edilene Farias Rozal

\section{Correspondência}

Rogerio Andrade Maciel - Universidade Federal do Pará - Campus Universitário de Bragança, UFPA. Alameda Leandro Ribeiro - Aldeia, Bragança, Pará, Brasil.

E-mail: rogeriom@ufpa.br-lenefarias@ufpa.br

Recebido em 03 de agosto de 2017

Aprovado em 11 de dezembro de 2017 